\title{
Fat and female fecundity: prospective study of effect of body fat distribution on conception rates /
}

\author{
Boukje MZZaadstra, Jacob C Seidell, Paul A H VanNoord, Egbert R te Velde, J Dik F/Habbema, \\ Baukje [rieswijk, Jan Karbaat
}

Abstract

Objectives-To study the effect of body fat distribution in women of reproductive age on fecundity.

Design-Prospective cohort study of all women who had entered a donor insemination programme.

Setting-One fertility clinic serving a large part of the midwest of the Netherlands.

Subjects-Of 542 women attending the clinic for artificial insemination for the first time, 500 women were eligible for study.

Main outcome measures-Probability of conception per cycle and number of insemination cycles before pregnancy or stopping treatment.

Results-A $0 \cdot 1$ unit increase in waist-hip ratio led to a $30 \%$ decrease in probability of conception per cycle (hazard ratio $0 \cdot 706 ; 95 \%$ confidence interval 0.562 to 0.887 ) after adjustment for age, fatness, reasons for artificial insemination, cycle length and regularity, smoking, and parity. Increasing age was significantly related to lower fecundity $(p<0.05)$; very lean and obese women were less likely to conceive $(p<0 \cdot 10)$ as were women with subfertile partners $(\mathbf{p}<0 \cdot 10)$. All other exposure variables were not significantly related to fecundity.

Conclusions-Increasing waist-hip ratio is negatively associated with the probability of conception per cycle, before and after adjustment for confounding factors. Body fat distribution in women of reproductive age seems to have more impact on fertility than age or obesity.

\section{Introduction}

Little is known about the effects of body fat distribution on reproductive function in women. Obesity is common among multiparous women ${ }^{1}$ but this may indicate that weight gain is the result of multiple pregnancies rather than a prerequisite for conception. ${ }^{2}$ Menstrual disorders have been found to be related to obesity as well as to a predominance of fat in the abdominal region. ${ }^{34}$ An abdominal type of fat distribution may be related to increased androgenicity of these women. ${ }^{56}$ Frisch suggested that underweight women would also have impaired reproductive function owing to a lack of oestrogen produced in adipose tissue. ${ }^{7}$ It is not known, however, whether body fat distribution has any effect on the ability to conceive (fecundity) independent of weight and menstrual disorders.

A population of women presenting for artificial donor insemination provides an opportunity to study prospectively determinants of fecundity while controlling for possible confounders. ${ }^{8}$ We studied 500 women aged 20 to 42 years presenting for artificial insemination to determine effects of body fat distribution while controlling for weight and other variables on the chance of conception.

Correspondence and requests

for reprints to:

Dr Zaadstra.

BMF 1993;306:484-7
Subjects and methods

From January 1986 to January 1988 all women attending a single fertility clinic for the first time $(n=542)$ were asked to participate in the study. Three women refused to participate. The 39 women who did not start treatment before January 1989 were excluded from the analyses. Thus 500 women filled in a questionnaire and had anthropometric measurements taken at intake.

The self administered questionnaire included questions on age, smoking habits, and other lifestyle characteristics. Regularity and length of the menstrual cycles, parity, degree of infertility of partner were ascertained by a doctor based on structured patient history. Women were wearing only light indoor clothing without shoes when anthropometric measurements were taken. These included weight $(\mathrm{kg})$, height $(\mathrm{cm})$, waist circumference at the umbilical level and hip circumference at the level of the widest symphisis (cm). All measurements were taken by one doctor. Quetelet's index $\left(\mathrm{kg} / \mathrm{m}^{2}\right)$ was calculated as a measure of total fatness (body mass index) and waist to hip ratio as a measure of body fat distribution.

Women were referred to the clinic by a gynaecologist or other specialist $(302,61 \%)$ or by a general practitioner $(101,20 \%)$ or came to the clinic on their own initiative $(85,17 \%)$. (No information was available on $12(2 \%)$.)

The main reasons for presenting for artificial insemination were infertility (azoospermia) or subfertility (oligospermia) of the partner (152 (30\%) and $236(47 \%)$ respectively). Other reasons included sterilisation of partner $(14,3 \%)$, genetic abnormalities of partner $(11$, $2 \%)$, no partner $(63,13 \%)$, and other reasons $(24,5 \%)$. For the analysis women with azoospermic or sterilised partners and women with no partner were categorised in the subgroup with infertile partners. Most women had tried to become pregnant for two or three years, and most $(412,82 \%)$ had never been pregnant when they entered the study.

Before the first insemination all women were examined by one doctor. The mean menstrual cycle length was 28 days. Cycle length was classified as short ( $\leqslant 24$ days) in 30 women, normal (25-35 days) in 431, and long ( $\geqslant 36$ days) in 39. At the start of the treatment 368 women reported having regular cycles (less than four days difference on average). Forty seven women with very irregular and long cycles had ovulation induced by clomiphene. None of the other women received drugs to improve fecundity at the start of insemination treatment.

The youngest woman entering the study was 20 years old, and 10 were 40 or older. Smoking was reported by 260 women.

\section{INSEMINATIONS AND FOLLOW UP}

Intracervical inseminations were applied in subsequent menstrual cycles. Timing was based on previous cycle length, examination of the cervical mucus, and basal temperature charts. Frozen semen was used from donors aged between 25 and 45 years with proved fertility (having fathered at least one child) and with sperm properties satisfying the World Health Organisation criteria.

Only first conceptions as a result of artificial in- 
semination were used for the analysis. Insemination was defined as successful if the woman did not menstruate when expected and subsequently had a positive pregnancy test result. The follow up period lasted three years, and the largest number of cycles observed was 33 .

\section{STATISTICAL METHODS}

The cumulative probability of conception by insemination cycle was calculated with Kaplan-Meier estimates for two waist-hip ratio groups.9 The 41 women who did not report the result of their last insemination cycle (over the entire follow up period) were recorded as not successful up to their last but one cycle. The anthropometric measures were missing for 11 women.

Univariate proportional hazard regression analysis $^{1011}$ was used to analyse the relation between probability of conception per cycle and each of the following variables separately: waist-hip ratio, body

TABLE I-Distribution of study population over categories of studied variables and percentages of pregnant women within 12 insemination cycles

\begin{tabular}{lcr}
\hline & $\begin{array}{c}\text { No }(\%) \\
\text { of women } \\
(\mathrm{n}=489)^{\star}\end{array}$ & $\begin{array}{c}\text { No } \% \text { ) } \\
\text { pregnant after } \\
12 \text { cycles }\end{array}$ \\
\hline Variable & & \\
Waist-hip ratio: & $32(7)$ & $20(63)$ \\
$<0 \cdot 70 \dagger$ & $99(20)$ & $50(51)$ \\
$0 \cdot 70-0 \cdot 75$ & $146(30)$ & $69(47)$ \\
$0 \cdot 75-0 \cdot 80$ & $138(28)$ & $57(41)$ \\
$0 \cdot 80-0 \cdot 85$ & $74(15)$ & $24(32)$ \\
$\geqslant 0 \cdot 85$ & & \\
Body mass index $\left(\mathrm{kg} / \mathrm{m}^{2}\right):$ & $104(21)$ & $42(40)$ \\
$<20 \cdot 0$ & $303(62)$ & $145(48)$ \\
$20 \cdot 0-25 \cdot 0 \dagger$ & $60(12)$ & $29(48)$ \\
$25 \cdot 0-30 \cdot 0$ & $22(5)$ & $4(18)$ \\
$\geqslant 30 \cdot 0$ & & $34(51)$ \\
Age (years): & $67(14)$ & $113(49)$ \\
$20-24 \dagger$ & $229(47)$ & $56(43)$ \\
$25-29$ & $131(27)$ & $17(27)$ \\
$30-34$ & $62(13)$ & \\
$\geqslant 35$ & &
\end{tabular}

^ For 11 women no anthropometric measurements available.

tReference category. For waist-hip ratio and body mass index upper limits are exclusive.

TABLE II-Univariate and multivariate proportional hazard analysis of waist-hip ratio, age, body mass index, reasons for artificial insemination, cycle length, cycle regularity, smoking, and parity on probability of conception per cycle over total follow up period ${ }^{\star}$

\begin{tabular}{|c|c|c|c|c|c|c|}
\hline \multirow[b]{2}{*}{ Variable } & \multicolumn{3}{|c|}{ Univariate analysis } & \multicolumn{3}{|c|}{ Multivariate analysis } \\
\hline & $\begin{array}{l}\text { Hazard } \\
\text { ratio }\end{array}$ & $\begin{array}{l}\text { 95\% Confidence } \\
\text { interval }\end{array}$ & p Value & $\begin{array}{c}\text { Hazard } \\
\text { ratio }\end{array}$ & $\begin{array}{l}\text { 95\% Confidence } \\
\text { interval }\end{array}$ & $\mathrm{p}$ Value \\
\hline Waist-hip ratio $(0 \cdot 1)$ & $0 \cdot 704$ & 0.568 to 0.871 & $<0.001$ & $0 \cdot 706$ & 0.562 to 0.887 & $<0.0025$ \\
\hline $\begin{array}{r}\text { Age: } \\
23 \\
27 \\
31 \\
37\end{array}$ & $\begin{array}{l}1.000 \\
0.977 \\
0.866 \\
0.603\end{array}$ & $\begin{array}{l}0.763 \text { to } 1.251 \\
0.605 \text { to } 1.240 \\
0.382 \text { to } 0.952\end{array}$ & $<0.0025$ & $\begin{array}{l}1 \cdot 000 \\
0.970 \\
0 \cdot 869 \\
0.638\end{array}$ & $\begin{array}{l}0.750 \text { to } 1.253 \\
0.597 \text { to } 1.266 \\
0.396 \text { to } 1.027\end{array}$ & $<0.05$ \\
\hline $\begin{array}{l}\text { Body mass index: } \\
19 \cdot 0 \\
22 \cdot 3 \\
26 \cdot 4 \\
33 \cdot 1\end{array}$ & $\begin{array}{l}0 \cdot 854 \\
1.000 \\
0 \cdot 901 \\
0 \cdot 367\end{array}$ & $\begin{array}{l}0.675 \text { to } 1.073 \\
0.749 \text { to } 1.084 \\
0.152 \text { to } 0.886\end{array}$ & $<0.05$ & $\begin{array}{l}0.837 \\
1.000 \\
0.939 \\
0.431\end{array}$ & $\begin{array}{l}0.662 \text { to } 1.058 \\
0.775 \text { to } 1.139 \\
0.171 \text { to } 1.087\end{array}$ & $<0 \cdot 10$ \\
\hline \multicolumn{3}{|c|}{ Reason for artificial insemination: } & NS & & & $<0 \cdot 10$ \\
\hline $\begin{array}{l}\text { Infertile partner } \\
\text { Subfertile partner } \\
\text { Other reasons }\end{array}$ & $\begin{array}{l}1 \cdot 000 \\
0 \cdot 778 \\
1 \cdot 238\end{array}$ & $\begin{array}{l}0.597 \text { to } 1.013 \\
0.734 \text { to } 2.088\end{array}$ & & $\begin{array}{l}1 \cdot 000 \\
0 \cdot 726 \\
1.254\end{array}$ & $\begin{array}{l}0.555 \text { to } 0.950 \\
0.738 \text { to } 2.130\end{array}$ & \\
\hline $\begin{array}{l}\text { Other reasons } \\
\text { Cycle length (1) }\end{array}$ & $\begin{array}{l}1.238 \\
0.999\end{array}$ & $\begin{array}{l}0.734 \text { to } 2.088 \\
0.974 \text { to } 1.026\end{array}$ & NS & $\begin{array}{l}1.254 \\
1.003\end{array}$ & $\begin{array}{l}0.738 \text { to } 2.130 \\
0.974 \text { to } 1.033\end{array}$ & NS \\
\hline Cycle regularity & 0.899 & 0.66 to 1.23 & NS & 0.886 & 0.642 to 1.221 & NS \\
\hline Smoking & $0 \cdot 870$ & 0.675 to 1.123 & NS & 0.914 & 0.704 to 1.187 & NS \\
\hline Parity & 1.015 & 0.717 to 1.435 & NS & 0.811 & 0.566 to 1.162 & NS \\
\hline
\end{tabular}

The relations were analysed by classes if the variable was categorical (cycle regularity, reason for insemination, smoking, parity), linear equation if the variable was continuous and significantly not quadratical (cycle length, waisthip ratio), and quadratic equation (variable +variable $e^{2}$ if addition of quadratic was significant (body mass index, age). Significance of variables was based on the effect of adding the parameters to the null model (univariate analysis) or the model with all other parameters (multivariate analysis).

For cycle regularity, smoking, and parity the hazard ratios express the difference of the second class with the first and for cycle length and waist-hip ratio the hazard ratios express an increase of 1 day or 0.1 unit respectively. For body mass index and age four values were chosen (medians of the classes in table I). The hazard ratio and confidence intervals were calculated for these values, where the highest value was taken as "baseline." The result is analogous to the presentation of other variables when it is taken into account that many other values could have been chosen. Consequentially the significance of the parameters cannot be deduced from confidence intervals.

${ }^{\star} \mathrm{N}=\mathbf{4 4 8}$ women, due to missing values in one of the exposure or confounding variables.

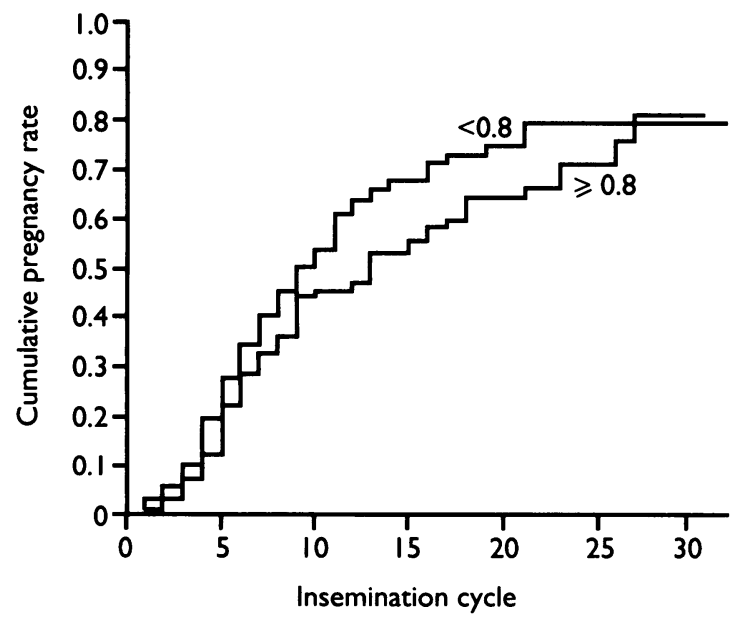

Cumulative pregnancy rate in 489 women having artificial insemination according to waist-hip ratio (277 women had ratio $<0.8$ and 212 a ratio $\geqslant 0.8)$. Kaplan-Meier logrank $p=0.0085$

mass index, age, regularity and length of menstrual cycle, smoking, parity, degree of infertility of partner. Multivariate proportional hazard regression ${ }^{1011}$ was used to analyse the relation between waist-hip ratio and probability of conception per cycle while controlling for the above variables. Unadjusted and adjusted hazard ratios and $95 \%$ confidence intervals were calculated. Both regression analyses were calculated from data on 448 women because of missing values in one of the exposure or confounding variables.

\section{Results}

Insemination was successful within 12 cycles in 226 women, not successful in 274 women, including 38 women with an unknown result. Table I shows the distribution of the women according to waist-hip ratio, body mass index, and age, and the percentage that became pregnant in each category. The distribution of age, waist-hip ratio, and body mass index of the 38 women lost to follow up was not significantly different from that of women with known outcome $(p>0.05)$. Abdominal fat preponderance (waist-hip ratio $\geqslant 0 \cdot 80$ ) was quite common (212 women). The percentage of women who became pregnant fell with increasing waist-hip ratio from $63 \%$ to $32 \%$. Women with a body mass index under $20 \mathrm{~kg} / \mathrm{m}^{2}$ were less likely to become pregnant than those with an index of $20-24.9 \mathrm{~kg} / \mathrm{m}^{2}$. Only 22 women were obese (body mass index $\geqslant 30 \mathrm{~kg} / \mathrm{m}^{2}$ ). Just four of these women became pregnant, suggesting a curvilinear relation between weight and fecundity. The percentage of pregnant women declined with older age and among the 62 who were 35 years or older only $17(27 \%)$ became pregnant.

The figure shows that the cumulative pregnancy rate by insemination cycle for women with waist-hip ratios $<0.80$ (pear shape) was significantly higher than for women with ratios $\geqslant 0 \cdot 80$ (apple shape) $(p=0 \cdot 008)$. Because of the small number of women completing 24 cycles or more the suggestion in our data that both groups will eventually have the same pregnancy rate, must be interpreted with caution.

Table II shows the unadjusted hazard ratios and $95 \%$ confidence intervals for the effect of waist-hip ratio, body mass index, age, regularity and length of cycle, smoking, parity, and reason for artificial insemination on probability of conception per cycle. Waist-hip ratio, age and body mass index were separately related to probability of conception per cycle. The multivariate proportional hazards regression in table II shows that the relation between waist-hip ratio and probability of conception per cycle, after controlling for all the other 
mentioned variables, remained essentially the same: waist-hip ratio yielded the highest independent significant contribution to probability of conception per cycle (hazard ratio $0 \cdot 706,95 \%$ confidence interval 0.562 to $0 \cdot 887)$.

\section{Discussion}

This study shows that increasing waist-hip ratio is associated with fecundity in healthy women, independently of age, fatness, length and irregularity of menstrual cycle, parity, degree of infertility of partner, and smoking habits. Both underweight and overweight women had a lower chance of becoming pregnant than women with normal weight, although this effect was greater for the obese than for the lean women. In addition, increasing age was associated with a reduced conception rate, which agrees with the results of our previous studies. ${ }^{12} 13$

\section{WAIST-HIP RATIO}

Hartz et al showed that in about 12000 American women aged 20-39 years participating in a slimming programme the degree of obesity and waist-hip ratio were independently and positively related to the prevalence of reported irregular menstruation, oligomenorrhoea (cycles longer than 36 days), and hirsutism. ${ }^{3}$ Such a relation has been explained as the result of increased androgenicity. ${ }^{5614}$

Based on information of cycle length and cycle irregularity in the period before insemination only $9 \%$ of the women in our study required clomiphene to regulate their cycle. Moreover, no obvious hirsutism was present in any of the women. Our study population therefore contained mainly healthy women of normal weight with apparently normal cycles, which makes comparison with the American study impossible.

Obese women or women with abnormal fat distribution with normal length of cycles (25-35 days) may have less regular cycles than women of normal weight and fat distribution. If this were true the decreased chance of conception could be explained by difficulties in timing of insemination, because timing may be less precise and therefore less successful in women with less regular cycles. However, we found no relation between abnormal fat distribution or obesity and cycle regularity or whether ovulation had to be induced. Therefore, after correcting for all these potentially confounding factors, the highly significant relation between waisthip ratio and the chance of conceiving, essentially remained the same (table II). The reasons for our finding remain unclear. Insulin resistance (which is clearly associated with abnormal fat distribution or obesity $)^{15}$ at an early stage might increase the androgenic microenvironment of the follicle thus decreasing oocyte quality and the chance of conceiving before androgen levels are raised in serum and before cycles become irregular. Moreover, recent findings suggest that increased levels of luteinising hormone, which may also be associated with hyperinsulinaemia, might decrease the spontaneous chance of conceiving and increase spontaneous abortion rates. ${ }^{16}$ Unfortunately, no pretreatment endocrine profiles were available in our study.

Weight loss often restores normal cycle regularity ${ }^{17}$ and sex hormone concentrations in obese women, ${ }^{18}$ which indicates that obesity itself and not primary endocrine dysfunction is the cause of the reproductive problems. Further research is necessary to investigate mechanisms responsible for the low conception rate in normal weight women with an increased waist-hip ratio.

\section{OTHER FACTORS AFFECTING FECUNDITY}

We also observed a tendency of a reduced chance of conception in women with a body mass index under 20 $\mathrm{kg} / \mathrm{m}^{2}$. The association between leanness and fertility has been extensively explored by Frisch, who has suggested that menstruation and ovulatory cycles can only start above a certain threshold ratio of lean body mass to fat mass. ${ }^{7}$ At body weights close to the required minimum women may still have anovulatory cycles even if they are menstruating because of a lack of peripherally produced oestrogen in adipose tissue. ${ }^{7}$ The problem can be reversed by gaining weight. ${ }^{7}$ However, this explanation does not hold for our results because most of the lean women in our population had regular cycles with biphasic basal body temperatures and did not require induction of ovulation. Moderate weight loss seems to lead to subtle ovulation disorders and therefore to decreasing fecundity.

Changes in weight and waist-hip ratio during the three year follow up period could have led to misclassification of women. However, it is known that body mass index on average changes only $0.10 \mathrm{~kg} / \mathrm{m}^{2}$ a year. ${ }^{19}$ Likewise no appreciable changes in waist-hip ratio occur with small fluctuations in weight. ${ }^{20}$ Proportional hazard regression analysis over a 12 cycle follow up yielded essentially the same results as that over the total follow up period.

Length and regularity of menstrual cycle were based on structured patient history at the start of the treatment. Prospective information on cycle variability during treatment would have led to potential selection bias. A minimum number of three cycles is needed to estimate variability, and women with low waist-hip ratios-that is more fertile women-would be more likely to be excluded from such an analysis, leading to an under-estimation of the relation between waist-hip ratio and fecundity.

Smoking has been associated with delayed conception. ${ }^{21}$ In our study women who smoked had lower conception rates, though this did not reach significance. In the adjusted analysis subfertility of the partner became indicative for the fertility of the woman because of the fact that within this subgroup women with lower fertility are over-represented among those entering a donor insemination programme..$^{22}$

CONCLUSIONS

In summary, in a prospective study of healthy women presenting for artificial insemination treatment we observed that increasing waist-hip ratio was negatively associated with the probability of conception per insemination cycle, before and after adjustment for age, fatness, cycle characteristics, smoking, parity, degree of infertility, and partner.

Our results seem to agree with recent findings of a breast cancer study among postmenopausal women by Sellars et $a l^{23}$ They observed that a high waist-hip ratio, low parity, and greater age at first pregnancy were more important risk factors for breast cancer among women with a family history of the disease than among those without such a history. However, older age at first pregnancy and fewer children were not independent factors. They were unable to determine whether this risk profile reflected cultural inheritance or difficulty in becoming pregnant. Our results suggest that the second is true: women with high waist-hip ratio have difficulty in becoming pregnant.

As the prevalence of a high waist-hip ratio among healthy women is larger than the prevalence of obesity (15\% and $5 \%$ respectively in our study) body fat distribution apparently has more impact on fertility than obesity.

Our findings are based on a cohort of women seeking insemination treatment because their partners had a fertility problem. Thus the population of women is primarily selected by the fertility of the partner and not the women and probably is a fair reflection on 
the normal population of women. ${ }^{8}$ Though our results need replication, this suggests that our results may be applicable to women attempting to conceive naturally.

The authors thank the women who participated in the study and the staff of Bijdorp Laboratories for their invaluable help; S P Verloove-Vanhorick and J J Radder for critically reading the manuscript: $\mathrm{C} W \mathrm{~N}$ Looman for constructive help; $M M$ van der Klaauw, $L M$ Rhodenborgh for support in data handling; and $M$ Huls-van Vliet for secretarial help.

1 Hartz AJ, Barboriak PN, Wong A, Katayama KP, Rimm AA. The association of obesity with infertility and related menstrual abnormalities in women. Int $f$ Obesity 1979;3:57-73.

2 Newcombe RG. Development of obesity in parous women. $f$ Epidemiol Community Health 1982;36:306-9.

3 Hartz AJ, Rupley DC, Rimm AA. The association of girth measurements with disease in 32856 women. Am 7 Epidemiol 1984;119:71-80.

4 Rogers J, Mitchell GW. The relation of obesity to menstrual disturbances. N Engl f Med 1952;247:53-5.

5 Evans DJ, Hoffman RG, Kalkhoff RK, Kissebah AH. Relationship of androgenic activity to body fat topography and metabolic profiles in premenopausal women. 7 Clin Endocrinol Metab 1983;57:304-10.

6 Seidell JC, Cigolini M, Charzewska J, Ellsinger BM, Biase G di, Björntorp P, et al. Androgenicity in relation to body fat distribution and metabolism in 38 year old women-the European fat distribution study. $f$ Clin Epidemio 1990;43:21-34.

7 Frisch RE. Fatness and fertility. Sci Am 1988;258:70-7.

8 Noord-Zaadstra BM van, Karbaat J, te Velde ER, Habbema JDF, Van der Maas PJ. The study of risk habits in reproductive and perinatal epidemiologic research: the use of a donor inseminated population of women. Paediar Perinat Epidemiol 1989;3:11-8.

9 Kaplan EK, Meier P. Non-parametric estimation from incomplete observa tions. Fournal of the American Statistical Association 1958;53:457-81.
10 Cox DR. Regression models and life tables. Fournal of the Royal Statistical Society [series B] 1972;34:187-202.

11 Aitkin MD, Anderson AO. Statistical modelling in GLIM. Oxford: Clarendon Press, 1989.

12 Noord-Zaadstra BM van, Habbema JDF, Karbaat J, Van der Maas PJ. Conceptiepercentages bij donorinseminatie; een onderzoek by 659 vrouwen die met vers donorsemen werden geinsemineerd. Ned Tijdschr Geneeskd 1980;124:581-7.

13 Noord-Zaadstra BM van, Looman CWN, Alsbach HA, Habbema JDF, te Velde ER, Karbaat J. Delaying childbearing: effect of age on fecundity and Velde ER, Karbaat J. Delaying childbearing:

14 Friedl KE, Plymate SR. Effect of obesity on reproduction in the female. foumal of Obesity and Weight Regulation 1985;4:129-45.

15 Pasquali R, Antenucci D, Casimiri F, Venturoli S, Paradisi R, Fabbri R, et al

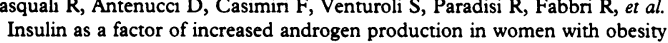
and polycystic ovaries. $\mathcal{F}$ Endocrinol Invest 1987;10:575-9.

16 Regan L, Owen EJ, Jacobs HS. Hypersecretion of luteinizing hormone, infertility, and miscarriage. Lancet 1990;336:1141-4.

17 Mitchell GW, Rogers J. The influence of weight reduction on amenorthea in obese women. N Engl f Med 1953;249:835-7.

18 Grenman S, Ronnema T, Irjala K, Kaihola HL, Gross M. Sex steroid, gonadotrophin, cortisol and prolactin levels in healthy, massively obese women: correlation with abdominal fat cell size and effect of weight reduction. I Clin Endocrinol Metab 1986;63:1257.

19 Rookus MA, Burema J, Hof van't MA, Durenberg R, Hautvast JGAJ. The development of body mass index in young adults. II. Interrelationships of level, change and fluctuation, a four-year longitudinal study. Hum Biol 1987;59:617-30.

20 Shimokota H, Andres R, Coon PJ, Elahi D, Muller D, Tobin JD. Studies in the distribution of body fat. II. Longitudinal effects of change in weight. Int f Obesity 1989;13:455-64.

21 Baird DD, Wilcox AJ. Cigarette smoking associated with delayed conception. fAMA 1985;253:2979-83.

22 Emperaire JC, Gauzere-Soumireu E, Audebert AJM. Female fertility and donor insemination. Fertil Steril 1982;37:90-3.

23 Sellers TA, Kushi LH, Potter JD, Kaye SA, Nelson CL, McGovern PG, et al. Effect of family history, body-fat distribution, and reproductive factors on the risk of postmenopausal breast cancer. $N$ Engl f Med 1992;326:1323-9.

(Accepted 9 December 1992)

\title{
Diary keeping in asthma: comparison of written and electronic methods
}

\author{
M E Hyland, C A P Kenyon, R Allen, P Howarth
}

Department of Psychology, University of Plymouth, Plymouth PL4 8AA $M$ E Hyland, reader C A P Kenyon, senior lecturer

University Department of Medicine, Southampton General Hospital, Southampton SO9 4XY R Allen, medical student P Howarth, consultant physician

Correspondence to: Dr Hyland.
Abstract

Objective-To determine the extent to which symptom diaries of asthmatic patients are inaccurate or based on retrospective recall.

Design-Comparison of electronic and pencil and paper diaries. Both forms were completed twice daily at home for 14 days.

Setting-Outpatient clinic.

Subjects-24 asthmatic outpatients also tested for severity of asthma and for anxiety.

Results-More sessions were missed in the evening than in the morning for both types of diaries. Significantly more retrospective entries were made in the evening ( 26 entries, 14 patients) than in the morning (6 entries, 3 patients). Discrepant entries of peak expiratory flow accounted for $15 \%$ of those made on the appropriate day, and three quarters of patients made at least one discrepant entry. Variation in peak expiratory flow was significantly related to number of discrepancies and number of missing days, and anxiety score was significantly related to number of missing days. About a fifth of written entries may have errors.

Conclusion-Poor diary completion may result from having unreasonable expectations of patients and giving incomplete instructions. Electronic, time coded diaries could ensure better quality of records.

\section{Introduction}

Daily recording of diary cards of subjective and objective assessments of the severity of disease is commonly used to monitor chronic conditions, such as asthma, which exhibit an intrinsic variability. Self completed diaries are preferable to single questionnaires or clinic based consultation because accurate recall of symptoms may be affected by memory bias ${ }^{1}$ and single measures may be misleading. The validity of the diary method requires, however, that patients complete their diaries on the day stated rather than retrospectively, and that the patient's record-for example, of peak expiratory flow-is accurate. Few researchers who use this method regularly will not have doubted, at one time or other, that these assumptions are not always met. For example, symptom diaries that have been completed in blocks of different coloured ink arouse a suspicion that the patient may have been completing the diary in blocks of days rather than daily. Some researchers try to counteract this problem by frequently collecting diary forms, ${ }^{2}$ but this is a burdensome procedure and the actual extent to which diaries are inaccurate or based on retrospective recall is unknown.

Developments in electronic diaries allow the problem of retrospective recall to be tested experimentally. The Asthma Question Box is a modified Psion Organiser that is programmed to ask patients questions about their symptoms and to allow them to record peak expiratory flow. The computer is also programmed automatically to store the actual date of data entry, without displaying this information.

The purpose of this study is to compare results from the Asthma Question Box with a conventional paper and pencil symptom diary to obtain information about missing records, retrospective completion (from an analysis of electronic date records), and accuracy (from comparison of data entry by the two methods).

\section{Methods}

As part of a larger study in which asthmatic outpatients were told that assessments were being 